\title{
Ficción y poesía en el Perú contemporáneo ${ }^{1}$
}

\section{(Fiction and Poetry in Contemporary Peru)}

\author{
Marco Martos Carrera ${ }^{2}$ \\ Universidad Nacional Mayor de San Marcos, Perú
}

resumen

Panorama descriptivo y analítico de las principales tendencias de la literatura peruana, de la segunda mitad del siglo xx. Se hace particular hincapié en las manifestaciones de su narrativa y del discurso poético.

\section{abstract}

The article describes and analyzes the main tendencies of Peruvian literature in the second half of the twentieth-century, with particular emphasis on narrative and poetic discourse.

Palabras clave: literatura hispanoamericana, literatura peruana contemporánea, narrativa peruana del siglo $\mathrm{xx}$, poesía peruana del siglo xx

Keywords: Spanish-American literature, contemporary Peruvian literature, 20th-century Peruvian narrative, 20th-century Peruvian poetry

Puede decirse que la prosa de ficción nació en el Perú en la pluma del Inca Garcilaso (1539-1616). El célebre escritor insertó hermosos pasajes de su propio magín en su elaborada visión del Imperio Incaico, pero hubieron de pasar tres siglos para que surgiese otro escritor de envergadura capaz de encandilar a sus lectores con relatos perdurables. Ricardo Palma es el escritor en prosa por antonomasia

1 Recibido: 9 de marzo de 2013; aceptado: 25 de septiembre de 2013. Artículo elaborado en relación con la conferencia impartida en la Universidad Nacional, Heredia, Costa Rica, 4 de noviembre de 2014.

2 Departamento Académico de Literatura de la Facultad de Letras y Ciencias Humanas. Correo electrónico: marcomartos9@hotmail.com.

$$
L_{\text {etras }} 54 \text { (2013), ISSN 1409-424X; EISSN 2215-4094 }
$$


del Perú en el siglo xix. Nacido en 1833 y muerto en 1919, llena con su pluma décadas de buena literatura pues fue el creador del género literario llamado «tradiciones» que la posteridad ha recogido tal como él lo creó y practicó. Sus Tradiciones Peruanas, pequeños relatos con alguna base real y con mucha imaginación, conocidos por todos los peruanos, expresan con punzante ironía, risa socarrona, asuntos de la vida diaria del país durante casi cuatro siglos. La obra de Palma recoge de manera muy clara, la manera de hablar el español de los peruanos y tiene su correlato en su actitud académica de defender el habla americana. Palma vivió al mismo tiempo que Machado de Assís y tiene parecida presencia en la cultura del Perú que el gran narrador de lengua portuguesa en la cultura del Brasil.

A principios del siglo xx el Perú tuvo un extraordinario escritor. Abraham Valdelomar, (1888-1919) como Palma, es un escritor que los peruanos conocemos desde la escuela y nos acompaña toda la vida. Pocas veces nació en nuestro país un individuo tan dotado para la literatura. En sus relatos, sabe combinar con inigualable destreza, aspectos de la vida diaria provincial y la literatura fantástica. Muerto en agraz, con más de cinco mil páginas escritas, Valdelomar es clara señal de la madurez de la literatura del Perú. Los siguientes grandes narradores son Ciro Alegría (1909-1967) y José María Arguedas (1911-1969). Cuando Ciro Alegría apareció en el ámbito de la literatura hispanoamericana como un narrador de fuerza inusitada. Sus tres libros iniciales ganaron premios internacionales y han quedado como modelos de la narrativa llamada indigenista. La serpiente de oro (1935), Los perros hambrientos (1938) y El mundo es ancho y ajeno (1941) son relatos que han resistido el paso del tiempo, conmueven y ponen en nuestra mesa de trabajo el tema apenas resuelto de las desigualdades sociales en el Perú contemporáneo. José María Arguedas es el par literario de Alegría y tuvo una carrera literaria de sostenido éxito. Mientras Alegría sitúa sus relatos en la sierra norte del Perú, Arguedas tiene como lugares preferentes a la sierra central y a la sierra sur, aunque una de sus grandes novelas el zorro de arriba 
y el zorro de abajo (1971) escoge como ámbito la ciudad costeña de Chimbote. Etnólogo y escritor, debemos a Arguedas la defensa denodada de las lenguas aborígenes, del derecho de las culturas originarias en América a vivir y a proyectarse al futuro. Arguedas nos dejó una novela extraordinaria: Los ríos profundos de 1958. Ese relato catapultó a su autor a la escena internacional. Por tu temática, el camino hacia la madurez de jóvenes adolescentes, ha sido comparado a $E l$ retrato del artista adolescente de James Joyce o a El retrato del artista cachorro de Dylan Thomas, pero por la originalidad de su prosa, de una finura lírica no vista en la literatura del Perú, por su amor a la naturaleza, intenso y natural, es una novela paradigmática, tal vez la más hermosa de la literatura del Perú. Hubo otros escritores, iniciados en los años cincuenta del siglo xx, que como Eleodoro Vargas Vicuña (1924-1997) tuvieron como espacio natural el mundo rural. Vargas Vicuña fue particularmente dotado para la escritura. Autor de tres colecciones de cuentos, Nahuín (1953), Taita Cristo (1960) y El cristal con que se mira (1975) es un estilista del idioma. Sus relatos, de una trabajada sobriedad, reelaboran el habla de los campesinos; con aparente opacidad, tienen relieves sorprendentes, a través de músicas, gritos, llantos, condensación de imágenes. Podemos advertir en la narrativa de Vargas Vicuña el magisterio de Juan Rulfo, y también, cosa sorprendente, el de Albert Camus y el existencialismo. Es un autor con quien está en deuda la crítica literaria peruana. Otro autor importante de esta tendencia es Manuel Scorza (1928-1983), poeta en sus comienzos que incursionó con éxito en la narrativa. Autor de la celebrada novela Redoble por Rancas (1970) alcanzó mucha popularidad con un ciclo que comprendió Garobombo el invisible (1972), El jinete insomne (1977), Cantar de Agapito Robles (1977), y La tumba del relámpago (1979). Sus relatos giran en torno a la lucha de los campesinos de la sierra central contra los hacendados y la empresa Cerro de Pasco Corp. entre 1959 y 1963 y están concebidos con una estructura circular. Escritas con mucha fluidez sus novelas atrapan al lector, lo introducen en un mundo donde apenas 
hay fronteras entre lo mágico y lo real y, al mismo tiempo, incorporan como personajes a ciudadanos conocidos en sus comunidades o en todo el territorio nacional, como ocurre con Genaro Ledesma, un destacado político de la izquierda peruana. Traducido a 35 idiomas, Scorza murió en un accidente en Madrid, junto con Marta Traba y Ángel Rama, cuando se encontraba en plena producción y alistaba nuevos libros. La corriente que explora el mundo rural se mantiene viva en otros escritores como Óscar Colchado (1947). Autor de libros de cuentos y de varias novelas es celebrado especialmente por su novela Rosa Cuchillo (1997), texto que combina el realismo mágico con la historia y que trata del enfrentamiento entre las fuerzas del orden y Sendero Luminoso. Rosa Cuchillo hace un viaje por los submundos andinos y aunque el modelo lejano puede ser Dante, la novela tiene audacia, potencia, originalidad. El favor de los lectores la mantiene como un texto leído por distintas promociones y se ha convertido en un referente literario para los jóvenes.

Carlos Eduardo Zavaleta (1928-2011) es uno de los novelistas más importantes del siglo xx. De formación universitaria rigurosa es autor de ocho novelas, varias colecciones de cuentos, recopilados en dos volúmenes Cuentos completos (1971) y un libro de ensayos El gozo de las letras (1997). Zavaleta, quien fue profesor de literatura inglesa en la Universidad de San Marcos, fue el difusor entre los jóvenes de las técnicas literarias de Dos Passos, Joyce y Faulkner. Versátil como pocos tiene una amplia temática en lo que escribe. Hijo de un telegrafista, viajo con su padre por muchos pueblos de la sierra y la costa peruanas en su niñez y adolescencia. Estudió medicina y luego se cambió a la Facultad de Letras de San Marcos, donde fue luego profesor. Como diplomático viajó a muchos lugares. En sus relatos encontramos vivos retratos de la vida en el agro, las luchas, los conflictos de los seres humanos en las ciudades de la costa, o lo que ocurre con los migrantes en el extranjero. Una de sus novelas notables es Los aprendices de 1974; otro relato que llama la atención es Un joven, una sombra de 1993 que reelabora con magistral prosa acontecimientos 
que se desarrollan en la Facultad de Medicina de la Universidad Nacional Mayor de San Marcos. Otro escritor de gran popularidad es Oswaldo Reynoso (1932). Entre sus libros destaca Los inocentes (1961), una apretada colección de cuentos que recoge el habla de los muchachos de la calle de extracción popular. El libro, celebrado por aquella razón, es ahora fuente de consulta de lingüistas y lexicógrafos que se documentan ahí sobre la forma de hablar de los jóvenes en los años sesenta. Profesor de lengua, Reynoso es un estilista, cuida mucho el lenguaje, dosifica las referencias populares, su prosa es puntillista, nerviosa, sorprendente. Sus adolescentes frecuentan billares y bares, prostíbulos, están plantados en las esquinas, lo más lejos que viajan es a la playa. Entre otros libros suyos merecen citarse En octubre no hay milagros (1965) y El escarabajo y el hombre (1970).

Nacido en Jauja en 1933, Edgardo Rivera Martínez es uno de los más destacados narradores del Perú contemporáneo. Desde que apareció en 1974 El visitante, una novela corta, Rivera fue recibido con beneplácito por la crítica literaria. Sus otros libros de cuentos, no han hecho sino confirmar sus dotes de narrador y llamar la atención sobre las condiciones de El unicornio (1963), un libro que había pasado desapercibido. Pero con la novela País de Jauja de 1993, fue que Rivera Martínez alcanzó una audiencia nacional e internacional. Alguna vez Goethe habló de la perpetua adolescencia del artista. Rivera Martínez, en el pórtico del libro, explica sus propósitos: hacer que el adolescente dialogue con el adulto que será y el adulto con el niño o adolescente que fue, con la finalidad de reinventar una y otra vez la propia vida. La novela privilegia el espacio de la ciudad de Jauja donde acudía gente de todo el Perú, de los países vecinos y de Europa en busca de la curación de la tisis pulmonar. Se formaba así una pequeña comunidad de gente cultivada que alternaba con el resto de la población. El relato muestra a Jauja como imagen de un Perú posible e integrado; en sus páginas alternan diversos personajes de muy variada edad y procedencia. Realista en algún sentido, la novela es también lírica en muchos pasajes. Los sentimientos básicos 
del ser humano, amor, odio, envidia, gratitud, expresados a través de la alegría, la nostalgia, el dolor, aparecen a lo largo de estas páginas, que dejan satisfecho al más exigente lector. En la tradición literaria occidental ha habido algunos novelistas que, en algún momento de su carrera, han reflexionado, en la propia ficción sobre la formación del artista. Los dos ejemplos más conocidos y estimados son los de James Joyce, que en 1914 escribió El retrato del artista adolescente, y el de Dylan Thomas, que en 1940 publicó El retrato del artista cachorro. Ambos textos fueron escritos en lo que se puede llamar la primera juventud de sus autores. La novela de Rivera, en cambio, aunque con el mismo tema, es un relato de madurez y muestra al escritor en plena posesión de sus recursos. Haríamos mal en tomar a País de Jauja como un testimonio histórico novelado de la Jauja de los años cuarenta. La Jauja de Rivera Martínez, más que a la pequeña urbe que conoció en su adolescencia, se parece a la ciudad irreal que inventa su irrefrenable nostalgia y termina siendo un hermoso castillo de palabras que cada lector va recreando mientras lee ese país de Jauja de los sueños. Así como los jaujinos sienten que algo de ellos mismos está representado en la novela, el resto de peruanos que hemos nacidos en distintos puntos del territorio nacional, sentimos que algo nuestro está en esas cinceladas páginas. Tal vez lo más valioso sea esa veta de cortesía, buen trato y afecto que predomina entre los personajes de la novela, que se alterna con humor, con bromas que surgen de improviso o que están preparadas y que contribuyen a variar en algo un relato que parece previsible.

Un narrador de gran fuerza expresiva es Enrique Congrains Martín (1932-2010). Sus dos libros más importantes Lima hora cero (1954), y No una sino muchas muertes (1958) sorprendieron por su temática. Era la primera vez que los marginales de la ciudad de Lima tenían protagonismo literario. Se trata de una colección de cuentos y de una novela. Esta se centra en la vida de Maruja, una joven de diecisiete años que es cocinera en un lavadero de pomos, dirigido por una mujer mayor y avara. Esta muchacha, gracias a un animus 
poderoso, enfrenta a todas las trampas que le ofrece la vida, en especial a los hombres que pretenden dominarla o violarla. En el lavadero están en calidad de verdaderos esclavos veinte locos. Las escenas son expresionistas: basurales visitados por gallinazos y cerdos, miseria por todos lados. Maruja recurre a todo lo que puede para salir adelante, seduce a un muchacho de su misma edad para convencerlo de que la ayude a hacer otro lavadero, lejos de la mujer pérfida, pero éste prefiere la comodidad de lo conocido a la aventura que la muchacha le ofrece. Maruja, al final de la novela, queda momentáneamente vencida, pero con una secreta esperanza. Nunca en la novela peruana del siglo xx había aparecido un personaje femenino de tanta fuerza y vigor. Nacido en 1934, Luis Loayza es un autor de culto en el Perú. En 1955 publicó un pequeño libro de cuentos. El avaro lo catapultó como una esperanza de la literatura peruana. Piel de serpiente (1964), fue una pequeña novela que dio pábulo para pensar que el relato corto era el marco ideal para la narrativa de Loayza. Después publicó el libro de ensayos El sol de Lima (1974) y tiempo después Otras tardes (1985), excelente libro de cuentos. Sus magras ediciones, y la escasa publicidad de sus escritos lo han encerrado en el círculo de los entendidos.

Con la aparición de Julio Ramón Ribeyro, Mario Vargas Llosa y Alfredo Bryce Echenique, la narrativa peruana alcanza niveles de difusión internacional muy grandes, cosa que no había ocurrido en el pasado. La obtención del Premio Nobel de Literatura en 2010, por Mario Vargas Llosa, no solo hace justicia a la obra de un gran narrador, sino que llama la atención sobre el proceso literario de un país que habiendo tenido escritores de mucha calidad como César Vallejo (1892-1938) o como Ventura García Calderón, (1886-1959), candidato al Premio Nobel en 1934, globalmente no tenía acceso a las editoriales más prestigiosas, ni posibilidades de traducción. Estos escritores tienen en común la voluntad de viajar, de salir de lo conocido para ir a lo desconocido, de considerar a literatura fundamentalmente como un asunto de formas, de manejo diestro del 
lenguaje, aunque ninguno de ellos ha desdeñado la temática social. Julio Ramón Ribeyro (1929-1994), cuentista, novelista, dramaturgo, está considerado como el narrador de la ciudad de Lima, pues la mayor parte de sus ficciones transcurren en la capital de Perú, en cierto sentido, le corresponde a él continuar la obra de Palma: a través de relatos breves hacer un gran fresco de la ciudad, aunque tiene cuentos que transcurren en otros lugares del país o en Europa. Sin embargo, no son los paisajes urbanos en centro de la narrativa de Ribeyro; lo que le interesa al narrador son los conflictos de los personajes, el conflicto de clases, no en un sentido político, sino en el diario vivir de la gente; la ambición y el fracaso, el deterioro, la frustración, la soledad, la muerte. Aunque autor de varias novelas, una de ellas muy hermosa, Crónica de San Gabriel de 1960, Ribeyro ha quedado en la memoria de los lectores como un eximio cuentista que utiliza su pluma como una linterna que alumbra los escondrijos menos conocidos de la ciudad y de las personas. Ribeyro parece tener preferencia por los «pobres diablos», los pobres entre los pobres, los de tristes oficios precarios, los recogedores de basura, los clientes de bares miserables. Hay un símil, una complementación más bien que puede hacerse entre los escritos de Ribeyro y la obra total de Sebastián Salazar Bondy, (1924-1965) célebre autor de un libro de ensayos Lima, la horrible de 1964, de numerosas obras de teatro, de libros de cuentos y poemas. Salazar ve la desdicha de una ciudad que sin ser moderna tiene los defectos contemporáneos, ínfulas aristocráticas de un pasado soñado más que vivido, donde pululan personajes sin norte conocido de todos los grupos sociales. Ribeyro, de su lado, tituló a la colección de sus cuentos completos La palabra del mudo y publicó pasajes de sus memorias con el título La tentación delfracaso.

¿Qué decir de Mario Vargas Llosa que no sea conocido por los lectores? En la literatura peruana del siglo xx hay dos nacimientos claros de la literatura peruana, dos libros emblemáticos que señalan una mayoría de edad. Otras literaturas tuvieron tempranamente grandes autores, a la literatura italiana le nació en el siglo xiii, Dante, la 
literatura española tuvo en el xvi a Cervantes, la literatura inglesa a Shakespeare, la literatura portuguesa a Camoens también en el siglo xvi. La literatura peruana escrita en español, frente a las europeas, es joven, tiene solo cinco siglos. Pero en su quinto siglo de vida le nacieron César Vallejo y Mario Vargas Llosa. Los libros iniciales de estos dos escritores, Los heraldos negros de 1919, y La ciudad y los perros de 1963, marcan una novedad de gran importancia no solo en la literatura del Perú, sino en la literatura escrita en español. Nada es igual en poesía o en novela después de estos libros. Vargas Llosa introduce al español formas de narrar que no habían sido utilizadas y que venían del Faulkner, de Malraux, de Dos Passos, de las que había tenido noticia tanto por su voracidad intelectual, como por el magisterio de Carlos Eduardo Zavaleta (1928-2011), prolífico narrador y profesor universitario. Vargas Llosa construye su primera novela en ritmo binario, el mundo de la ciudad, y el mundo de los «perros», los cadetes del colegio Leoncio Prado. Un paraíso soñado y aludido en sordina y un infierno con sus círculos y sus despiadados castigos. Como en la novela El joven Törless de Robert Musil, el drama se desencadena por el robo de una prueba de química en el recinto escolar. El libro tiene potencia, embrujo, una áspera poesía. Nunca en el Perú un joven escritor había llegado tan lejos. La novela hacía presagiar una gran obra y los hados se han cumplido. La sucesión de libros publicados por Mario Vargas Llosa abarca miles de páginas y casi todos los géneros posibles. Los lectores estamos acostumbrados a abrir las páginas de los diarios para encontrar nuevos homenajes y premios a un escritor que con el premio Nobel en 2010 ha alcanzado todos los lauros más importantes que un escritor puede ganar. Pero los lectores tienen preferencias en la magnífica obra sin caídas de Mario Vargas Llosa, según un consenso en el Perú; se prefieren las novelas La ciudad y los perros (1963), La casa verde (1966), Conversación en la Catedral (1969), La guerra de fin del mundo (1981), La fiesta del chivo (2000); Libros a los que hay que agregar La orgía perpetua: Flaubert y Madame Bovary (1975). Mario Vargas Llosa 
ejerce considerable influencia sobre escritores posteriores. Luis Urteaga Cabrera (1940) publicó en 1973 su novela Los hijos del orden, relato sobre una rebelión en una cárcel de menores que termina con la muerte terrible de los cabecillas y que hace «racontos» en cada una de las historias que ayudan a precisar las razones por las que esos jóvenes han sido detenidos. Otro escritor, Gerardo Benavides (1964) publicó Los años inútiles (2002), un retrato sombrío del Perú en la época del primer gobierno de Alan García (1985-1990). Lima aparece en el contexto de una crisis económica que aflige al país, llena de matones, asesinos, secuestros, personas desquiciadas.

Nacido en Lima, en 1939, Alfredo Bryce es un escritor muy popular. Egresado de la Universidad Nacional de San Marcos, en la que obtuvo el grado de Doctor en Letras, gozó de un éxito inicial, gracias a la obtención de una mención honrosa en el Concurso Casa de las Américas, de La Habana, Cuba, por su libro Huerto cerrado, escrito en 1968, aunque editado en 1970. El texto contiene doce relatos que se ocupan del mundo de la adolescencia de la clase alta limeña, en especial, las primeras experiencias sentimentales con sus consiguientes fracasos y el paso resignado a la vida adulta. El libro es, como lo define posteriormente su propio autor en sus Antimemorias «aquel libro de debutante en que intenté recrear algunas experiencias de mi adolescencia». También en 1970, otro libro suyo, Un mundo para Julius, fue presentado al Premio Biblioteca Breve de Barcelona, España. El premio no fue discernido, pero la publicación del libro le dio a Bryce una difusión en todo el ámbito hispanoamericano. El libro cuenta la vida de un niño - entre los siete y los doce años- hipersensible y heredero de una aristocrática familia limeña. Al contrario de lo que dijo la crítica inicialmente, los lectores de varias décadas después, que han consagrado, a través de la lectura y de opiniones escritas, a esta novela como una de las más interesantes del siglo xx, no ven en ella «la novela de la revolución peruana», ni una crítica mordaz a la aristocracia decadente. Bryce, como lo haría posteriormente en su novela No me esperen en abril, de 1995, 
observa, desde de la distancia que le confiere el humor, que es la marca de toda de su producción literaria, la sociedad oligárquica limeña, sus trivialidades, miserias y mezquindades que se esconden detrás de una aparente grandeza. A través del humor, Bryce penetra en la realidad de manera profunda y crea un estilo personal que tiene como núcleo central la oralidad, lo que significa la irrupción del lenguaje cotidiano en la literatura, una multitud de referencias literarias, una profunda ternura y un acercamiento, en contadas ocasiones, a situaciones trágicas. El personaje Julius, ese niño limeño hijo de una familia acaudalada, permanece en la imaginación de los lectores como algo de lo más hermoso salido de la pluma de un escritor peruano. Posteriormente, Bryce publicaría La felicidad ja ja (1974), Tantas veces Pedro (1977), donde los personajes ya no se limitan al mundo infantil o La vida exagerada de Martín Romaña (1981) cuyo protagonista, Martín Romaña, puede ser su alter ego (hecho con similitud al propio autor), pues uno y otro viven acontecimientos personales y político sociales similares. En 1985 aparece El hombre que hablaba de Octavia de Cádiz y en 1988, La última mudanza de Felipe Carrillo. En 1995 saldrá su libro autobiográfico Permiso para vivir (antimemorias) y también No me esperen en abril. En esta última novela Bryce nos narra en tercera persona la vida de Manongo Sterne, vástago de ingleses acriollados, personaje «tan distinto a los demás porque a su edad sólo veía la gravedad de las cosas de esta vida, sobre todo al amanecer y al anochecer». Se trata de un niño partido en dos, acusado de ser poco hombre por no pertenecer al mundo de los «matadores de hembritas», de los que sabe poner a las mujeres «seditas», al mundo de los desfiles militares, de las disciplinas con gritos. Este mismo muchacho es considerado un espíritu maligno por la Asociación de Padres de Familia del colegio Santa María y es expulsado del plantel. Sus padres deciden enviarlo interno a un colegio inglés de reciente creación «el más caro y británico colegio de América del Sur». Previamente a su partida conoce a Tere Mancini, su único y obsesivo amor. El colegio se inaugura en el mes de abril, 
que es por lo tanto el tiempo de separación de estos adolescentes que juramento tras juramento hablan de su trascendental amor. Manongo vivirá siempre en marzo. Como Julius, es símbolo de la inmadurez, es el personaje que no quiere crecer. Este libro, como casi todos los de Bryce, siendo ficción goza de las galas de las autobiografías, y bien puede llamarse una autobiografía ficticia de su autor. No me esperen en abril es una novela que nos habla de amistad y muerte, de amor, fidelidad y lealtad. Manongo es un personaje enamorado, noble, granuja, canalla, raro, celoso, amigo de sus amigos, un Julius crecido y también memorable. En 1997 Bryce publicó Reo de nocturnidad, libro que trata de las aventuras personales y literarias de un profesor de literatura en una universidad francesa. Como no es difícil de adivinar, el personaje se parece al propio Bryce.

Entre los años sesenta y ochenta del siglo xx aparecen narradores que se refieren a los negros de la costa. Antonio Gálvez Ronceros (Chincha 1931) está considerado por la crítica literaria y por numerosos lectores, como uno de los cuentistas más valiosos de la tradición peruana. Su primer libro de cuentos, Los ermitaños de 1962, es objeto de culto. Ese breve conjunto de relatos, que desde el punto de vista de la técnica literaria son de una maestría ejemplar muestran también un profundo conocimiento del lenguaje del campesino de la costa del Perú. El segundo libro de cuentos de Gálvez Ronceros, Monólogo desde las tinieblas de 1975 se propuso captar lo peculiar del lenguaje de los personajes negros de Chincha, especialmente el humor que suele aparecer en el habla diaria. Esta actitud ya aparecía en el primer libro de Gálvez Ronceros, pero en ese texto, como en los relatos de Arguedas o de Alegría, podía distinguirse la voz del autor, cultivada con arreglo a las más exigentes normas gramaticales, y las voces de los personajes que atienden al modo corriente de expresarse de los campesinos. En Monólogo desde las tinieblas, el autor se vuelve un orífice de la prosa. Cada frase del léxico popular está trabajada con fina delectación. Los hechos jocosos que se narran, las situaciones insólitas que se plantean, con un lenguaje que sólo utiliza las palabras 
indispensables, son un vehículo adecuado para conocer la visión del mundo del campesino, de un realismo descarnado, de una fina ironía y con elementos de carácter mágico. La voz que narra estos relatos, o es la del mismo protagonista o es la de alguien semejante a él. Ya no existe ese distanciamiento, propio de los primeros relatos. En 1988, Gálvez Ronceros publicó otro breve conjunto de cuentos, Historias para reunir a los hombres. Se trata de relatos de extensión mínima de fuerte intención didáctica. Como se ha dicho muchas veces, el conocimiento de las estructuras narrativas que tiene Gálvez Ronceros, es ejemplar, pero en esto se parece a otros maestros del género como el dominicano Juan Bosch o el cubano Onelio Cardoso. La marca que lo diferencia de éstos o de diversos notables cuentistas, es el manejo peculiar del humor, que es el recurso estilístico más característico de su prosa. Para decirlo en pocas palabras, el tránsito entre sufrimiento y diversión, la solución a situaciones cotidianas, pasa casi siempre por un mecanismo humorístico. Y, como sucede en la vida real, el mejor humorista es el que conserva una actitud de seriedad. Gálvez Ronceros, como Vargas Vicuña, como Loayza o como Ribeyro, es muestra exacta de que el cuento como técnica y como realidad, tiene plena vigencia en el Perú de hoy.

Gregorio Martínez Navarro, nacido en Coyungo, Nazca, en 1942, es uno de los más destacados representantes, junto con Antonio Gálvez Ronceros, de la literatura de los negros en el Perú. Ambos escritores, para evitar la confusión evidente con la «novela negra» que es la literatura policial, han elegido una frase para referirse a sus escritos: literatura de campiña. Y efectivamente, los escritos de Martínez y de Gálvez aluden al campo costeño y sus personajes casi siempre son campesinos de la etnia negra. Ha escrito, entre otros, los siguientes libros: Tierra de caléndula (1977), Canto de sirena (1985), La gloria del piturrín y otros embrujos del amor (1985) y Crónica de músicos y diablos (1991). Si el primero de sus libros, Tierra de calén$d u l a$, es un conjunto de cuentos, de sabor clásico, que reúne relatos con personajes negros en su mayoría, los libros que siguieron son 
difícilmente clasificables. Puede decirse que Canto de sirena es una novela, pero es una narración peculiar, hasta cierto punto inimitable. Se trata de reflexiones sobre la vida que se hace un personaje negro de mucha edad, Candelario Navarro, quien aparte de caracterizarse por un humor, al mismo tiempo reflexivo y desenfadado, va llevando el apunte, de cada una de las aventuras amorosas que ha tenido durante su dilatada existencia. El texto muestra la sabiduría popular en distintos terrenos: en el conocimiento de la cocina popular, de la flora y fauna de Nazca, de las conductas de hombres y mujeres. Gregorio Martínez es en cierto sentido un continuador de la prosa vigorosa de Enrique López Albújar, quien en 1928 en su novela Matalaché, describe los desenfadados amores de un negro con una mujer blanca en los arenales de Piura. Martínez reivindica su filiación popular, lo hace a través de su límpido lenguaje que recoge y da lustre al habla de los negros, pero al mismo tiempo, en una serie de citas, muestra su aspiración de ser reconocido como un actor de la literatura del canon. El español que utiliza es aproximativo, a ratos arcaizante, lleno de neologismos, en conflicto permanente con la escritura académica. Por eso no llama la atención que en algunos textos de no ficción, que publica en diarios y revistas, Martínez entra en conflicto con la propia Academia de la Lengua a la que le reclama por su lentitud en incorporar palabras populares al diccionario. No otra cosa hizo Ricardo Palma en las postrimerías del siglo xix. Crónica de músicos y diablos es un relato donde la historia se mezcla con la literatura y donde se narra la historia de los negros cimarrones de Huachipa. Con Gregorio Martínez se afirma la identidad afroperuana en nuestra cultura.

Nacido en Piura en 1940, Miguel Gutiérrez se ha convertido en uno de los novelistas más leídos y comentados. Ha publicado las siguientes novelas: El viejo saurio se retira (1969), Hombres de caminos (1968), La violencia del tiempo (1991), La destrucción del reino (1992), Babel, el paraíso (1993), Poderes secretos (1995), El mundo sin Xochitl (2001), Una pasión latina (2011). También es autor de libros de ensayos, entre ellos: La generación del 50: un mundo dividido 
(1988). Cuando apareció la primera novela de Gutiérrez pocos advirtieron que ese texto abría una verdadera caja de Pandora, el territorio favorito de un novelista de garra lleno de conflictos y de afectos. El viejo saurio se retira es una novela de aprendizaje en el sentido que lo son la novela de James Joyce Retrato del artista adolescente y Retrato del artista cachorro de Dylan Thomas. Pero más que a esos dos textos, el de Gutiérrez tiene semejanza con El estudiante de Törless de Robert Musil. Se trata de un conjunto de jóvenes que en una difícil maduración se enfrentan a la omnímoda religiosidad de un colegio católico en Piura. Un crítico, José Miguel Oviedo, advirtió en el momento de la aparición del libro, que había elementos comunes con la novela picaresca. Literalmente tenía razón, pero los otros valores de la novela no fueron cabalmente percibidos. Gutiérrez traía ya en ese primer libro, una prosa diferente, nerviosa, variada, de intensidad lírica, precisamente como había sido la prosa del primer Dos Passos en los años veinte de la centuria pasada. Gutiérrez demoró bastante en entregar una segunda novela. Entretanto fundó la revista Narración en 1966 con otros escritores como Oswaldo Reynoso, Juan Morillo, Gregorio Martínez, Augusto Higa. Podría decirse que la crítica peruana no se percató en los años setenta, que estaba apareciendo un novelista original. Pero cuando se publicó Hombres de caminos en 1988, ya hubo cierto consenso. Gutiérrez volvía a ocuparse de Piura, pero esta vez salía de los muros escolares y mezclaba su pluma con las clases populares, con la variedad de conflictos de campesinos con patrones, generalmente edulcorados por los escritores regionales o aparentemente olvidados en la memoria de la gente. Esa temática de Hombres de caminos será desarrollada con más vigor en La violencia del tiempo, para muchos, la novela más interesante de Gutiérrez. Al iniciarse los años noventa del pasado siglo ya Gutiérrez es un novelista cuajado, dueño de sus recursos expresivos y puede, mediante los artilugios de un gran creador, mezclar acontecimientos de su espacio favorito, Piura, con otros conocidos por él mediante el estudio y la información como la Comuna de París de 1870. En La destrucción 
del reino vuelve Gutiérrez a esos espacios piuranos, llenos de polvo, sol y conflicto. Una pizca de nostalgia tiñe su prosa vigorosa. Babel, el paraíso, una novela muy bien lograda de Gutiérrez y no suficientemente celebrada por la crítica nacional, se ambienta en oriente, podríamos decir que en China, aunque la obra no es suficientemente explícita en ese punto. Con páginas de prosa impecable, el tema de fondo, es la metafísica del poder. Gutiérrez ha sabido trasminar su experiencia en China, el conocimiento, aunque fuere indirecto de los mecanismos del poder en una sociedad cerrada, a una parábola sobre la condición humana. Simultáneamente Gutiérrez explora la esfera de los afectos entre personas de diferentes culturas. El mundo sin Xochitl, vuelve a los espacios de Piura. Novela de gran belleza, acabada, de gran fuerza y perfección formal. Esta vez se nos presenta una Piura en algunos aspectos misteriosa. Gutiérrez se atreve con un tema sombrío: el incesto entre hermanos y lo hace con delicadeza casi religiosa. Y el pecado, como en otras grandes novelas, se asocia a enfermedad y muerte. Al final de la novela, como en Los ríos profundos de José María Arguedas, una epidemia de peste, invade la comarca. En los años sesenta del siglo xx, hubo en Trujillo un importante grupo literario. De Trilce salieron tres narradores de importancia: Juan Morillo Ganoza, (1939), Jorge Díaz Herrera (1941) y Eduardo González Viaña (1941). Diferentes entre sí, son una muestra palpable de tenacidad literaria. Morillo es dueño de una prosa impecable que va ofreciendo sus galas en cada una de sus novelas ambientadas casi todas en el mundo rural de La Libertad. González Viaña sabe aprovechar bien las coyunturas literarias, de la vida de un curandero, salta a una novela sobre César Vallejo. Jorge Díaz Herrera es un fino estilista, un narrador exquisito. Su libro Alforja de ciegos reeditado varias veces, es de una rara belleza.

Isaac Goldemberg (Chepén 1945) es un novelista y poeta que introduce el mundo de los judíos en la literatura peruana. Su novela más conocida La vida a plazos de don Jacobo Lerner (1976) narra la historia de un migrante judío de origen ucraniano que llega al Perú y 
tiene en Chepén relaciones con una joven Virginia a la que abandona para instalarse en Lima donde regenta un burdel, al mismo tiempo que se relaciona con otra mujer, Juana. Lo interesante de la novela es que muestra la situación del migrante, si vida fragmentada, el hecho de dirigir un prostíbulo, lo convierte en un paria en su propia comunidad, donde tampoco otros personajes son felices. En poesía, Goldemberg, destaca por la intensidad de su verbo, que partiendo de sus pertenencias al mundo judío y al Perú, logra penetrantes observaciones que atañen a toda la humanidad. Así como el mundo judío ha llegado a la literatura peruana, también otros hijos der migrantes chinos o japoneses han empezado a destacar. Mencionamos aquí a Sum Kam Wein (1951) quien publicó en 1985 un notable libro de relatos Un tramo del final y a Augusto Higa Oshiro (1947), hijo de migrantes japoneses que por representar a lo marginales de origen abigarrado e incierto en sus cuentos Que te coma el tigre (1977) o en su novela El final del porvenir de 1992. Es curioso cómo un novelista cuajado como Carlos Thorne, (1923) con buenas novelas como Papá Lucas, (1987), El señor de Lunahuaná (1989) o El encomendero de la adarga de plata (1999), y que publica tanto el Perú como en España, sea más conocido allende las fronteras que dentro del territorio nacional. Con un profundo manejo de la técnica literaria, la que viene de Joyce y Malcom Lowry, Thorne, merece mayor atención de la crítica especializada. Con un sostenido prestigio destaca también José Bravo Amézaga, (1939) autor entre otras, de una célebre novela Barrio de broncas (1971) que le ha dado una sostenida popularidad. Bravo, es además, uno de los escasos cultivadores de la novela histórica. Del mismo modo, recostado sobre la historia, Luis Enrique Tord (1942), ha elaborado una obra literaria valiosa. De otro lado, Harry Belevan (1945), fino estilista, amante de la literatura fantástica, ha publicado varias novelas y colecciones de cuentos. En su libro Escuchando detrás de la puerta de 1975, relaciona su propia capacidad creativa, con las autores consagrados como Dino Buzzatti o Jorge Luis Borges, modificando de modo radical cuentos de esos autores. 
Otro autor de calidad es Carlos Calderón Fajardo (1946), autor de las novela La colina de los árboles (1981), Así es la pena en el paraíso (1984), El fantasma nostálgico (2006). Todos estos autores contribuyen de modo decisivo a crear una comunidad literaria, tanto de escritores como de lectores. En ese sentido un caso paradigmático es de Alonso Cueto (1954) quien empezó su carrera literaria en 1983 con su novela La batalla del pasado y poco a poco, de manera muy clara, ha ido logrando el favor del público con una carrera literaria persistente, sin prisa y sin pausa, con notables novelas como Grandes miradas (2003) que le han dado una atención internacional. Leído y comentado en distintas lenguas, Alonso Cueto ha sabido transitar de un tipo de narración intimista a otra que no rehúye los grandes temas que ha preocupado a la sociedad peruana como el terrorismo y la corrupción. La prosa de Cueto, como la de Onetti, uno de sus autores favoritos, procura penetrar en las oscuras motivaciones de los hombres, sin cargas las tintas, gracias al humor que aparece en muchos de sus relatos. Cronwell Jara Jiménez, es un prolífico autor; una de sus primeras novelas, Patíbulo para un caballo (1989) sorprendió gratamente a la crítica. Dueño de una imaginación desbordante e naturaleza expresionista, Jara conoce bien el mundo rural de Piura, interesado en todo el fenómeno literario, dirige talleres literarios y ha mostrado particular interés por la literatura infantil.

En la década de 1980 la narrativa peruana pasó por un periodo dramático: eran tiempos de crisis económica y de violencia generalizada. En esos años los nuevos narradores como Fernando Ampuero (1949) o Guillermo Niño de Guzmán (1955) prefirieron optar por una literatura íntima y personal lejos de los proyectos colectivos de los escritores anteriores como Oswaldo Reynoso o Miguel Gutiérrez. Buscaban que el universo de su narrativa se sostuviese por el mundo interno de los personajes. Aunque es justo decir que Ampuero en sus novelas y cuentos posteriores se fue metiendo en la piel y en la mente de personajes de la calle. Fue en este momento que apareció un narrador como Jaime Bayly con su novela No se lo digas a nadie 
(1994) que conmocionó a la sociedad peruana, pues se atrevía con un tema casi tabú. Bayly abordaba el uranismo de modo directo, yendo más lejos que lo que había escrito en los años treinta José Diez Canseco. Es cierto que la escritura de Bayly en su ahora larga carrera de novelista, no es novedosa, pero es correcta y sus temas audaces. Los lectores más cuidadosos por supuesto reconocen la marca de Yukio Mishima, como el inspirador de muchos de sus relatos, pero también conviene señalar que Bayly tiene otra característica del escritor japonés: el afán de sorprender, de ser no solamente un novelista, sino una estrella que llama constantemente la atención. Trajo en su novela una novedad: la representación de las clases altas, con su doble moral, su racismo. Bayly maneja bien los diálogos, sabe captar la atención del lector. Pero el autor que mejor representa este momento es Mario Bellatín, autor nacido en México, de padres peruanos que con su relato Salón de belleza toca otro tema tabú en la literatura reciente: el sida. La relación entre literatura y enfermedad es larga en la historia universal, baste pensar en Edipo rey o en La peste de Camus, pero en décadas recientes, después del descubrimiento de la penicilina, la literatura no daba mucha cabida a la enfermedad. Bellatín, que ha continuado su carrera literaria en México con pulcra prosa se atreve a contar la historia de un peluquero que ha contraído el terrible mal. Otro estilista de la narrativa es Iván Thays quien publicó en 1992 Las fotografías de Francis Farmer, luego Escenas de caza (1996), El viaje interior (1999) y La disciplina de la vanidad (2000). Thays es uno de los novelistas más estudiosos de las técnicas literarias. Dueño de una información sobre narrativa excepcional, profesor de talleres literarios, tiene grandes posibilidades de convertirse en un autor celebrado. Con numerosos libros de cuentos publicados y algunas novelas como Libro de mal amor (2001) y Neguijón (2005), Fernando Iwasaki, peruano, nieto de japoneses, es uno de los escritores que más llama la atención en los últimos años. Un panorama de la narrativa peruana reciente sería incompleto sin la mención a los escritos de ficción de las mujeres. Con brillo propio han destacado 
en los últimos años Carmen Ollé (1947) y Pilar Dughi (1956-2003). Esta última se proyectaba como una gran novelista. Había publicado dos colecciones de cuentos y la novela Puñales escondidos (1998). Estaba logrando una particular originalidad cuando la muerte truncó su carrera. Carlos Yushimito (1977) es el autor novel que más llama la atención en el panorama editorial del Perú. Autor de varias colecciones de cuentos: El mago (2004), Las islas (2006), Equis (2009) y Lecciones para un niño que llega tarde (2011) ha conseguido rápidamente notoriedad internacional y es leído en todo el orbe hispano. Ha sido sindicado como uno de los escritores jóvenes más importantes del habla española. Tibor Fisher, en palabras recogidas en el último libro de Yushimito ha dicho: « $i$ Un peruano de antepasados japoneses que vive en Providence y escribe sobre el Brasil? Carlos Yushimito es un claro exponente del siglo xxi. Todos están en todas partes. O como diría Joyce, aquí está todo el mundo».

La poesía escrita en español en el Perú tiene una vigorosa tradición. Nacida en el siglo xvi en las coplas de incipientes cronistas soldados, alcanzó inusitado vigor en los versos de Amarilis, al parecer una monja que escribió hermosísimos versos a Lope de Vega, de un refinamiento bastante extraño en nuestras tierras ásperas. Los tres siglos de virreinato español marcaron una separación entre las culturas aborígenes y la cultura occidental. En el plano social todavía estamos esperando la síntesis, pero en el plano de la poesía en particular y de la literatura en general, si algo caracteriza a los escritores nacidos en el Perú y que escriben en español, es la utilización de un español andino con un sustrato aborigen que aparece sin excepción posible en todos ellos, de manera obvia casi siempre, o de forma escondida en un puñado de líridas. Un buen ejemplo de lo que se dice es Mariano Melgar, poeta que escribe en los albores de nuestra independencia y que trajo al verso castellano formas de concebir la poesía que pertenecen a la cultura quechua y que son fácilmente reconocibles. Pero hubo que esperar algunas décadas, hasta 1844, para que nos naciera un gran poeta: Manuel González Prada. Reputado 
con justicia como un prosista marmóreo, un patriota ejemplar, capaz de levantar entusiasmos colectivos en momentos de un pesimismo nacional, es al mismo tiempo el iniciador de la poesía contemporánea en el Perú. Dueño de una instrucción excepcional, conocía diversas lenguas, en particular el francés y el alemán; y como en otra época hizo Garcilaso de la Vega, el poeta de los príncipes españoles, introdujo en la poesía del Perú ritmos y estrofas desconocidas en estos lares, consiguiendo así una poesía verdaderamente diferente y original también por su temática, porque manifestó, más que nadie en su época, un profundo afecto por todos los excluidos. Sus Baladas peruanas siguen constituyendo un modelo de poesía hispanoamericana. González Prada ha sido clasificado por los críticos al movimiento modernista, aunque nació bastante antes que Darío y empezó de manera independiente sus exploraciones literarias y métricas, rubro este último en el que fue investigador destacado. La brillantez en la poesía de Manuel González Prada puede compararse con la prosa de orífice de Manuel Gutiérrez Nájera y por su estudio de la versificación española, recuerda a André Bello y al poeta boliviano Ricardo Jaimes Freire.

La poesía contemporánea del Perú sería inexplicable sin César Vallejo (1892-1938). Existiría, pero sería menos lograda y menos audaz. La presencia de un gran poeta marca su tiempo y el que sigue. Si Vallejo no hubiera escrito, no solamente estaríamos privados de su poesía, sino de algo que atañe al trabajo colectivo de los poetas de hoy: una dosis de confianza en la lengua, la seguridad de que hubo uno nacido entre nosotros que fue verdaderamente ejemplar como escritor y que en sus versos alcanzó una originalidad no vista desde el tiempo de Quevedo. El poeta dominicano Manuel del Cabral ha señalado que hay muchos poetas que escriben bien en el siglo xx, pero ninguno en lengua española alcanza la profundidad y la originalidad de César Vallejo. Y Roberto Paoli, el estudioso italiano de la poesía peruana, ha dicho lo mismo de otra manera. Nadie puede dudar de la maestría verbal de José Santos Chocano, pero como él hubo numerosos poetas en 
toda Hispanoamérica. Tampoco se puede discutir la calidad literaria de José María Eguren; posee un aire de familia con los poetas simbolistas franceses y con los crepusculares italianos. Vallejo es el poeta en lengua española más diferente a otros en el siglo xx. Pasó de una etapa de aprendizaje en Los heraldos negros (1919) a otra de experimentación absoluta en Trilce (1922), el libro de vanguardia más característico de la lengua española que solo admite comparación con Altazor (1931), del poeta chileno Vicente Huidobro. La originalidad más profunda la alcanzó Vallejo con Poemas humanos y España aparta de mí este cáliz, aparecidos de forma conjunta en 1939, aunque del libro sobre España existe una edición anterior. Lo central en la poesía de Vallejo, aparte de un dominio formal reconocido por estudiosos y aficionados, es el sufrimiento, la expresión «en carne viva» del dolor. Vallejo habla como uno más de la tribu de los excluidos. En su tiempo fue hasta cierto punto marginal. Vivió en París al mismo tiempo que Hemingway, Gide, Aragon, Breton, aunque no tuvo trato con ninguno de ellos; con el tiempo ha devenido en poeta central del español. Como Kafka o Celan para la lengua alemana, como Eliot para la lengua inglesa, como Proust para la lengua francesa.

La aventura literaria de Vallejo fue muy importante, única. No se ha dicho, pero ahora conviene subrayarlo: había una distancia abismal entre Vallejo y otros poetas de su tiempo en el Perú. Las críticas que le hicieron cuando publicó Trilce parecen ahora de una pasmosa ingenuidad. Había mucha distancia entre Vallejo y los demás, no solamente en los logros poéticos, sino también en la formación literaria.

A partir de 1930 la sociedad peruana empieza a lograr una cierta democratización en el terreno literario. Son varios los poetas que destacan de manera nítida: Emilio Adolfo Westphalen, César Moro, Xavier Abril, Martín Adán. Tres de ellos estuvieron bajo el aura surrealista: Moro, Wetsphalen y Abril, aunque solo Moro tuvo una militancia tangencial en el movimiento. Debemos a Westphalen una poesía que descarta la hipertrofia del yo, centrándose en el discurrir verbal, que quiere ser natural como el agua corriente. Poesía que 
explora los meandros de la subjetividad, el yo profundo, y tiene sin embargo una dicción suave y melancólica. Moro fue un poeta de la causa surrealista que no vaciló en romper con el propio Breton, que sostuvo una ardiente polémica con Huidobro, que defendió a capa y espada su poesía del cuerpo y del amor uranista. Abril es un caso curioso en la poesía del Perú. Surrealista de primera hora, fue desprendiéndose lentamente del movimiento y adoptó formas clásicas. Pasó de la relación con Breton a otra con Vallejo, por el que tuvo verdadera devoción como crítico. El caso más insólito de estos poetas de los años treinta es Martín Adán, quien vivió entre 1908 y 1985. Ningún poeta peruano como él ha tenido más leyenda. De musa fecunda, es un bardo preocupado solo por escribir, dejando de lado todo afán de publicación. Sus poemas hechos al desgaire eran cuidadosamente reunidos por personas compasivas. En su juventud, Emilio Adolfo Westphalen le copiaba sus versos a máquina; en su senectud, las manos amicísimas de Juan Mejía Baca recogían sus poemas. Adán es claro antecedente de lo que sería en los años sesenta del siglo xx Luis Hernández, poeta emblemático para muchos jóvenes de hogaño.

El grupo más importante del Perú en el siglo xx es el de la promoción de los años cincuenta. Ellos han llevado el nombre del Perú más allá de nuestras fronteras, como no había ocurrido desde la época de Vallejo. Blanca Varela, (1926) Jorge Eduardo Eielson, (1924-2003) Carlos Germán Belli (1927), Wáshington Delgado (1927-2003), Javier Sologuren (1921-2004) han acostumbrado a los lectores de los diarios a ver sus nombres como ganadores de importantes premios de poesía. Más allá de ese detalle, lo importante, otra vez, es el grado de originalidad alcanzado por cada uno de ellos. No siguen ninguna moda sino que hacen su propio camino. En ese sentido, de todos ellos, el poeta más diferente es Carlos Germán Belli.

Los poetas que se inician en los años sesenta estuvieron marcados por un sino trágico. Javier Heraud, la promesa más nítida de ese tiempo, fue virtualmente asesinado en Madre de Dios en 1963; Luis Hernández, Juan Ojeda y Hernando Núñez encontraron la muerte de 
manera infausta. Pocos alcanzaron a tener una obra sólida, entre ellos Antonio Cisneros (1942) Rodolfo Hinostroza (1941), Hildebrando Pérez (1941) Los tres conocieron de cerca la poesía conversacional y fueron evolucionando a una poesía personal que se ha difundido en toda Hispanoamérica. Un reciente libro de cuentos de Rodolfo Hinostroza se titula Cuentos de extremos occidente. Ese rótulo nos sirve para una reflexión. La literatura de nuestros países es occidental, ¿qué duda cabe? En el caso del Perú nuestra literatura de Garcilaso a Vargas Llosa, de Amarilis a José Watanabe, es una literatura de extremo occidente. Y si la lengua es nuestra patria más clara, la marca de nuestro lenguaje es el carácter andino del español del Perú. Todos «tendemos la cama» y no «hacemos la cama», vamos a las «chacras» y no a los «huertos», y todos, como Jorge Eduardo Eielson, en la noche, cuando queremos tocar la luna, tocamos la «luna» de nuestros anteojos negros.

En la década de 1970 aparecieron varios poetas de calidad, Elqui Burgos, (1946), José Watanabe (1946-2007), Abelardo Sánchez León (1946), Jorge Pimentel (1946) y Tulio Mora (1946) Junto a ellos destaca Enrique Verástegui (1951), autor de un temprano libro excelente En los extramuros del mundo (1972). De todos ellos, destaca José Watanabe, que tiene una voz original, uno ojo de pintor para describir situaciones, una intensa capacidad para auscultar al ser humano, su condición material débil, fácil presa de la enfermedad y de la muerte. Poesía intensa, ajena al desgarro romántico, vecina, si cabe, a la de la gran escritora Emily Dickinson. Watanabe, como Higa en narrativa, junta una tradición japonesa bien asimilada, con la vigorosa lección de la poesía peruana. Carlos López Degregori (1952) es tal vez el poeta de propuesta más interesante y diferenciada de las últimas décadas. Con un estilo que ha ido forjando libro a libro, a través de una vida dedicada a la escritura, ha llamado la atención de un reputado crítico y poeta de la generación llamada del cincuenta: Américo Ferrari. Autor de unos quince libros de poesía, está, como dice el título de unos de sus libros «lejos de todas partes». Su 
poesía insular, recoge la tradición de la orilla opuesta al realismo, en ciertos momentos parece fantasmal y quimérica, pero siempre está ligada a los problemas esenciales del hombre.

Mario Montalbetti (1953) apareció en poesía con un libro muy interesante Perro negro (1978) anunciaba la aparición de un notable escritor. Los vaticinios se cumplieron pues sus libros posteriores, Llantos Elíseos (2002) Fin del desierto (2005), Cinco segundos de horizonte (2005) y Ocho cuartetas contra el caballo de paso peruano (2008) lo muestran como un escritor que conoce bien la tradición occidental de la poesía, que sabe como pocos que la originalidad es algo bastante complejo para los poetas y que se consigue solo con un castigado rigor. Montalbetti, al lado de López Degregori, constituye algo de lo más original de la poesía del Perú en estas décadas. Otros poetas muy interesantes son Enrique Sánchez Hernani (1953) Róger Santiváñez (1956), Eduardo Chirinos (1960). Los tres han ido variando sus propuestas literarias. Sánchez mantiene, sí una atención al rumor de la calle, mientras Santiváñez ha evolucionado de una poesía ríspida a otra neobarroca, vigente en los escritores en lengua castellana en los Estados Unidos. Chirinos, en cambio, atendiendo siempre a las exigencias de la modernidad, escribe una poesía de resabios clásicos. Los años setenta también marcaron la aparición de varias mujeres dedicadas a la poesía. Una de ellas, Enriqueta Beleván publicó Poemas al estilo de una pintura ingenua (1978) y Poemas de la bella pájara hornera de 1984. En ella los valores femeninos tradicionales. Delicadeza, gracia, ternura, precisamente aquellos que rechazaba combativamente el feminismo militante, aparecen en todos sus matices y en toda su intensidad. Lo que no hay en su escritura son esos suspiros románticos que malogran cualquier poesía. En su escritura Beleván es tierna sin ser débil, dulce sin ser almibarada, soledosa, silenciosa militante de la poesía. De sus versos, donde tiembla una profunda emoción, podemos colegir que la poesía no es para ella otra cosa que la prolongación de su vida, una vida que el lector adivina plena de afectividad, que no ama el sufrimiento, 
pero que lo siente como una condición humana y que en medio de la desesperanza es capaz de llegar a la calma que precede a la luz. Observadora de los detalles, Enriqueta Beleván conoce como pocas mujeres los pliegues y repliegues del corazón, las sutilezas de los afectos, el emponzoñado alfileretazo del dolor; elegante y sobria a la vez, sabe expresar su mundo interior con las palabras exactas, ni una más ni una menos que las necesarias para comunicar su emoción. Es cierto que en todo el siglo xx hubo mujeres destacadas en poesía, empezado por Magda Portal, elogiada por Mariátegui en los años veinte, pero es a partir de los años setenta que hay una eclosión de mujeres con gran calidad: Carmen Luz Bejarano, Yolanda Westphalen, Sonia Luz Carrillo. Rosina Valcárcel, Ana María Gazzolo, Giovanna Pollarolo, Magdalena Chocano, Rocío Silva Santisteban, Doris Moromisato, Marcela Robles, Rossela Di Paolo, Esther Castañeda, Milka Rebaza, Mariela Dreyfus, Monserrat Álvarez. Finalmente hay que decir que la poeta emblemática de todo este tiempo es María Emilia Cornejo, muerta a los 21 años en 1972, dueña de una potente originalidad que pulió su estilo en el Taller de poesía de la Universidad Nacional Mayor de San Marcos y que ha dejado un puñado de poemas de indiscutible calidad. «La muchacha mala de la historia» como se llamó a sí misma, trascendió sus asuntos particulares para representar el punto de vista femenino en una época turbulenta para el conjunto de la sociedad.

Entre los poetas recientes que llaman la atención, conviene mencionar a Mauricio Medo (1965), Jorge Frisancho (1967). Lorenzo Helguero (1969), Victoria Guerrero (1971) Chrystian Zegarra (1971), José Carlos Irigoyen (1976), Paúl Guillén (1976), todos ellos autores de libros publicados, con algunos premios literarios, diferentes entre sí, pero que tienen en común, una voluntad de comunicar sus escritos a través del internet y las redes sociales. En un país donde hace muchos años no se conceden Premio Nacionales de la Cultura, ha habido otras formas de reconocimiento menos oficiales pero valiosas. Una de ellas es el Premio Copé de Petro Perú. 
Este premio, que permite conocer a nuevos escritores de todo el país ha privilegió en 2012 a dos escritores provincianos: Luis Fernando Cueto en narrativa y a Darwin Bedoya en poesía. Este hecho, que ya es una constante en la literatura peruana, prueba que ahora hay una democratización de la información y que en todo lugar del país pueden surgir escritores de calidad.

\section{Bibliografía panorámica de la literatura peruana contemporá- nea (ficción y poesía)}

Arroyo, Carlos. Hombres de letras (Historia y crítica literaria en el Perú). Lima: Ediciones Memoriangosta, 1992.

Belli, Carlos Germán. Poemas. Lima: Talleres Gráficos Villanueva, 1958. ---. Dentro \& Fuera. Lima: ed. de la Rama Florida, 1960.

---. ¡Oh, Hada Cibernética! Lima: ed. de la Rama Florida, 1961.

---. El pie sobre el cuello. Lima: ed. de la Rama Florida, 1964.

---. Por el monte abajo. Lima: ed. de la Rama Florida, 1966.

---. Sextinas y otros poemas. Santiago de Chile: Editorial Universitaria, 1970.

---. Asir la forma que se va. El libro de las decenas (antología de diez poemas). Lima: Cuadernos del Hipocampo, 1979.

---. En alabanza del bolo alimenticio. México: PREMIA editora, 1979.

---. Canciones y otros poemas. México: PREMIA editora, 1982.

---. Boda de la pluma y la letra. Madrid: Instituto de Cooperación

Iberoamericana, Ediciones Cultura Hispánica, 1985.

---. Más que señora, humana. Lima: Perla, 1986.

---. El buen mudar. Madrid: Ediciones del Tapir, 1986.

---. En el restante tiempo terrenal. Madrid: Ediciones del Tapir, 1988.

---. Antología personal. Lima: CONCYTEC, 1988.

---. Bajo el sol de la medianoche rojo. México: PREMIA editora, 1990. 
Bellini, Giuseppe. Historia de la literatura hispanoamericana. Madrid: Castalia. 1990.

Bendezú, Francisco. Arte menor. Lima: Escuela Nacional de Bellas Artes, 1960.

---. Los años. Lima: La Rama Florida, ilustraciones y viñeta de Fernando de Szyszlo, 1961.

---. Cantos. Lima: La Rama Florida, con viñeta de Fernando de Szyszlo y cinco reproducciones de Giorgio de Chirico, 1971.

---. El piano del deseo. (Jazz \& Poesía). Lima: separata de la revista Socialismo y Participación No. 21,1983.

Bueno, Leoncio. Al pie del yunque. Lima: Grupo Intelectual Primero de Mayo, 1966.

---. Pastor de truenos. Lima: Túngar, 1968.

---. Invasión poderosa. Lima: Túngar, 1970.

---. Rebuzno propio. Lima: Ediciones Arte/Reda, 1976.

---. La guerra de los runas. Lima: Túngar, 1980.

---. Los últimos días de la ira. Lima: edición del autor, 1990.

Carrillo, Francisco. Provincia. Lima: La Rama Florida, 1961.

---. Cristo se ha llevado toda la humildad del mundo. Lima: La Rama Florida, con viñeta de Szyszlo, 1961.

---. Cuzco. Lima: Colección Breve Follaje de la Rama Florida, 1962.

---. En busca del tema poético. Lima: La Rama Florida y de la Bi-

blioteca Universitaria, 1965. Contiene los libros publicados y

las colecciones inéditas «Brevedad del amor» $\mathrm{y}$ «Yaravíes».

---. Pequeños poemas comprometidos. Lima: La Rama Florida, 1967.

Chariarse, Leopoldo. Los ríos de la noche. Lima: Rímac, 1952.

---. La cena en el jardín. Lima: Instituto Nacional de Cultura, 1975.

Contiene: La cena en el jardin, Los sonetos de Spoleto y Los ríos de la noche. 
Cornejo Polar, Antonio. Historia de la literatura del Perú republicano. Lima: Mejía Baca. 1980.

Delgado, Washington. Formas de la ausencia. Lima: Editorial Le-

tras Peruanas, Biblioteca de escritores peruanos, 1955.

---. Días del corazón. Lima: Cuadernos de composición, 1957.

---. Para vivir mañana. Lima: edición del autor, 1959. Contiene además Canción española.

---. Parque. Lima: La Rama Florida, 1965.

---. Tierra extranjera. Lima: Perú Joven, 1968.

---. Destierro por vida. Lima: Carlos Milla Batres Ediciones, 1969.

---. Un mundo dividido. (Poesía 1951-1970). Lima: Casa de la Cultura del Perú, 1970.

---. Reunión elegida (Antología personal). Lima: SEGLUSA editores y Editorial Colmillo Blanco, 1987.

---. Historia de la literatura republicana; nuevo carácter de la literatura del Perú independiente. Lima: Rikchay. 1980.

Eielson, Jorge Eduardo. Reinos. Lima: separata de la revista de Historia No. 9, 1945. 2da. edición, Lima: Ediciones de la Clepsidra, 1973.

---. Canción y muerte de Rolando. Lima: La Rama Florida, 1959.

---. Mutatis mutandis. Lima: La Rama Florida, 1967.

---. Poesía escrita. Lima: Instituto Nacional de Cultura, 1976. Contiene toda la obra publicada agregándose varias colecciones de poemas: Doble diamante, Tema y variaciones, Habitación en Roma, Naturaleza muerta, Eros/iones, 4 estaciones, Canto visible, 4 textos y Papel.

---. Nuit obscure du corps. Noche oscura del cuerpo. París: Altaforte, 1983. Edición bilingüe traducida al francés por Claude Couffon.

Fernández Moreno, César (dir.). América Latina en su literatura. México: Siglo xxi. 1986. 
Ferrari, Américo. El silencio/Las palabras. Málaga, Cuadernos del Sur No. 20, 1972.

---. Espejo de la ausencia y la presencia. Málaga: Edición de Angel Caffarena, 1972.

---. La metamorfosis de la evidencia. Lima: ediciones de la Clepsidra 1974.

---. Tierra desterrada. Lima: Ediciones Arybalo, 1981.

---. Figura para abolirse. Trujillo: Ediciones SEA-Casa del artista, 1991.

Florián, Mario. Tono de fauna. Cajamarca: Talleres tipográficos El Trabajo, 1941.

---. Urpi (Canciones neo-Keshwas). Lima: Dirección de Educación Artística y Extensión Cultural, Ministerio de Educación Pública, 1945.

---. Poesía 1940-1950. Lima: Talleres gráficos P. L. Villanueva, 1954. Contiene: Noval, Area del Sol, Arte Mural, El Cantor mitimae (Serranilla y Pastoral).

---. Canto augural. Lima: Talleres gráficos P. L. Villanueva, 1956.

---. Poesía escrita 1940-1060. Lima: Escuela Nacional de Bellas Artes, 1961.

---. Pedro Palana (la multitud eterna del Perú). Lima: Compañía de Impresiones y Publicidad, 1965.

---. Obra poética, escogida (1940-1976). Lima: Librería Studium, 1977.

---. Habla de Pedro Palana. Lima: Imprenta Editorial Fidel Ramírez Lazo, 1980.

Franco, Jean. Introducción a la literatura hispanoamericana. Caracas: Monte Ávila. 1979.

Guevara, Pablo. Retorno a la creatura. Madrid: Cooperación Intelectual, 1957.

---. Los habitantes. Lima: La Rama Florida, 1965. 
---. Crónicas contra los bribones. Lima: Carlos Milla Batres Ediciones, 1967.

---. Hotel del Cuzco y otras provincias del Perú. Lima: Instituto Nacional de Cultura, 1971.

---. La quinta esencia de la desolación (Cía. Gémims Ltda.) En: Vaca Sagrada, Año I, No. 1, Lima, 1978.

Gutiérrez Correa, Miguel. La generación del cincuenta: un mundo dividido; historia y balance. Lima: Ediciones Séptimo Ensayo, 1988.

Henríquez Ureña, Pedro. Historia cultural y literaria de la América Hispánica. Edición de Vicente Cervera Salinas. Madrid: Verbum, 2007.

Huamán Cabrera, Félix. La generación del cincuenta en la literatura peruana del siglo XX. Tomo I. Volumen I. Lima: Universidad Nacional Enrique Guzmán y Valle. 1989.

López, Sinesio. El dios mortal. Estado, sociedad y política en el Perú del siglo xx. Lima: Instituto Democracia y Socialismo, 1991.

Martos, Marco (ed.). Documentos de Literatura N 1 - Trimestre abril, mayo, junio de 1993. Antología poética de la promoción 45/50. Lima: Masideas. 1993.

---. En las fronteras de la poesía. Ensayos literarios. Lima: Lápix, 2012.

Miranda, Efraín. Muerte cercana. Lima: Talleres gráficos Mercagraph, 1954.

---. Choza. Lima: Empresa Editora Humboldt, 1978.

---. Vida. Lima: Empresa Editora Humboldt, 1980. 
Monguió Luis. La poesía post modernista peruana. México: Fondo de Cultura Económica. 1951.

Oviedo, José Miguel. Historia de la literatura hispanoamericana. De Borges al presente. Tomo 4. Madrid: Alianza, 2002.

Quíspez Asín, Fernando. Paisajes para una emperatriz. Lima: Industrial Gráfica, 1963.

Ramírez, Luis Hernán. Soledad y sombra. Iquitos, 1957.

---. Sobre el dorso de la noche. Lima, 1965.

---. Piel o sombra amada. Lima: La lámpara azul, 1973.

---. El amor en el centro del mundo. Lima: La manzana mordida, 1991.

---. Gloriosa gota pura. Lima, 1992.

Romualdo, Alejandro. Poesía. (1945-1954). Lima: Mejía Baca \& P. L. Villanueva Ed., 1954. Contiene: La torre de los alucinados, Cámara lenta, El cuerpo que tú iluminas, Mar de fondo, España elemental y Poesía Concreta.

---. Edición extraordinaria. Lima: Ediciones de Cuadernos Trimestrales de Poesía, Festival del Libro de La Libertad, 1958.

---. Desde abajo. Lima: Ediciones Tawantinsuyo, Biblioteca Comprensión del Perú, s/f. Contiene: Mar de fondo, España elemental, y Poesía concreta.

---. Como Dios manda. México: Joaquín Mortiz, 1967.

---. El movimiento y el sueño. Lima: Gráfica Labor, 1971.

---. Cuarto mundo. Buenos Aires: Losada, 1972.

---. En la extensión de la palabra. Lima: Gráfica Labor, 1974.

--- Poemas. (Antología). La Habana: Casa de Las Américas, 1975.

---. Poesía Integra. Lima: Viva Voz, Gráfica Labor, 1986. Reúne todos los libros publicados. 
Rose, Juan Gonzalo. La luz armada. México: Ed. Humanismo, 1954. ---. Cantos desde lejos. Lima: Penta Ultra, 1957.

---. Simple canción. Lima: Forma y Poesía, 1960.

---. Las comarcas. Lima: Industrial Gráfica, 1964.

---. Hallazgos y extravíos. México: Fondo de Cultura Económica, 1968.

---. Informe al rey y otros libros secretos. (1963-1967). Lima: Carlos

Milla Batres, 1969. Contiene: Informe al rey, Discurso del hura-

ño, Los bárbaros, Abel entre los fieles y Panfleto de la soledad.

- Obra poética. Lima: Instituto Nacional de Cultura, 1974.

- Biografías breves de la vida breve. Lima: Colección de poesía Gárgola, 1975.

-Poesía. Lima: Editorial Colmillo Blanco, 1990. Contiene: Cantos desde lejos, Simple canción, Informe al rey y otros libros secretos, Hallazgos y extravíos, Cuarentena, Peldaños sin escalera y Canciones.

Ruiz Rosas, José. Sonetaje. Arequipa: Imprenta Rodríguez, 1951.

---. Esa noche vacía. Arequipa: Trilce, 1967.

---. Urbe/Retorno a tiempos. Arequipa: Homo, 1968.

--- La sola palabra. Lima: Ames, 1976.

---. Arakné. Lima: Perugraph, 1978. Dibujos de Cristina Gálvez.

---. Vigilia del cristal y de la bruma. Arequipa: Editores, 1978.

---. Tienda de ultramarinos. Arequipa: Urpillay, 1978.

---. Elogio de la danza. México: Universidad Nacional Autónoma de México, 1980.

---. Poesía reunida. Arequipa: Universidad Nacional de San Agustín, 1990. Contiene: Primeros poemas (19)1-1963), Urbe, La sola palabra, Arakné, Tienda de ultramarinos, Vigilias, Elogio de la danza, Llakiurpi, Diálogo a solas, Vecino de la muerte, Inventario permanente. 
Salazar Bondy, Sebastián. Voz desde la vigilia, Lima: Hermes, 1944.

---. Cuaderno de la persona oscura. Lima: Lumen, 1946.

---. Máscara del que duerme. En Poesía, Lima: Ministerio de Educación, 1949.

---. Tres confesiones. Buenos Aires: Cuarta Vigilia, 1950.

---. Los ojos del pródigo. Buenos Aires: Botella al Mar, 1951.

---. Confidencia en alta voz. Lima: Vida y Palabra, 1960

---. Vida de Ximena. Lima: Forma y Poesía, 1960.

---. Conducta sentimental. Bogotá: CELZA, 1963.

---. El tacto de la araña. Sombras como cosas sólidas. (Poemas

1960-1965). Lima: Francisco Moncloa, 1966.

---. Poemas. Tomo III. Obras de S. S. B., Francisco Moncloa Editores, 1967.

Sánchez, Luis Alberto. Derrotero para una historia cultural del Perú. Sexta edición. Lima: Emisa, 1989.

Scorza, Manuel. Las imprecaciones. México: El viento del pueblo, 1955. ---. Los adioses. 2a. ed. Festivales del libro. Lima: Centauro, 1960.

---. Desengaños del mago. Lima: Organización Festivales del Libro, 1961.

---. Réquiem para un gentilhombre. Lima: El Neblí, 1962.

---. El vals de los reptiles. México: Universidad Nacional Autónoma de México, 1970.

---. Obra poética. Lima: Promoción Editorial Inca (PEISA), 1990.

Sologuren, Javier. El morador. Lima: separata de la revista Historia (Lima), No. 8, 1944.

--- Detenimientos. Lima: Talleres de la imprenta Amauta, 1947. Ilustraciones de Fernando de Szyszlo.

--- Dédalo dormido. México: separata de la revista Cuadernos Americanos, 1949. Con grabado de Szyszlo.

---. Bajo los ojos del amor. México: Icaro, 1950. 
---. Otoño, endechas. Lima: separata de la revista Mercurio Peruano, 1959.

---. Estancias. Lima: La Rama Florida, colección El Timonel, 1960.

---. La gruta de la sirena. Lima: La Rama Florida, 1961.

---. Vida continua. Lima: La Rama Florida y de la Biblioteca Universitaria, 1966. 2a. edición, Instituto Nacional de Cultura, 1971.

---. Recinto. Lima: La Rama Florida, 1968.

---. Surcando el aire oscuro. Lima: Carlos Milla Batres ediciones, 1970.

---. Corola parva. México: La Máquina Eléctrica, 1977.

---. Folios de El Enamorado y la Muerte. Caracas: Monte Avila, 1980.

---. Jaikus escritos en un amanecer de otoño. Lima: separata de la revista Lienzo No. 6. Ilustraciones de Takahisa Shirayama, 1986.

---. Retornelo. Lima: Colmillo Blanco. Ilustraciones de Nobuko Tadokoro.

---. Catorce versos dicen... Madrid: Ediciones del Tapir, 1987.

---. Folios de El Enamorado y la Muerte \& El amor y los cuerpos.

Lima: SEGLUSA ediciones y Colmillo Blanco, 1988.

---. Poemas 1988. Madrid: Ediciones del Tapir, 1988.

---. Vida continua. Obra poética (1939-1989). Lima: Colmillo Blanco, Colección de Arena, 1989.

---. Un trino en la ventana vacía. Madrid: Ediciones del Tapir, 1992.

Tamayo Vargas, Augusto. Literatura peruana. Quinta edición. Lima: Peisa. 1993.

Valcárcel, Gustavo. Confín del tiempo y de la rosa. Lima: Universidad Nacional Mayor de San Marcos, 1948.

---. Poemas del destierro. México: América Nueva, 1956.

---. Cantos del amor terrestre. México: Espacios, 1957. Dibujo de la carátula de Diego Rivera.

---. 5 poemas sin fin. Lima: Perú Nuevo, 1959.

---. jCuba sí, yanquis no! Lima: Perú Nuevo, 1961.

---. Poesía revolucionaria. Lima: Perú Nuevo, 1962.

---. pido la palabra! Lima: Perú Nuevo, 1965. 
---. Pentagrama de Chile antifascista. Lima: editora Perú Nuevo, 1975.

---. Reflejos bajo el agua del sol pálido que alumbra a los muertos.

En: Haraui, No. 54 Año XVII, Lima, 1980.

---. Obra poética (1947/1987). Lima: Unidad, 1988. Contiene todos

los libros publicados, una colección de poesía inédita y abundante iconografía.

Varela, Blanca. Ese puerto existe (y otros poemas). Xalapa, México: Universidad Veracruzana, 1959.

---. Luz de día. Lima: La Rama Florida, 1963.

---. Valses y otras falsas confesiones. Lima: Instituto Nacional de Cultura, 1972.

---. Canto villano. Lima: Arybalo, 1978.

---. Canto villano. Poesía reunida, 1949-1983. México, Fondo de Cultura Económica, 1986. Contiene: Ese puerto existe (19491959), Luz de día (1960-1963), Valses y otras falsas confesiones (1964-1971), Canto villano (1972-1978), y Otros poemas (1978-1983).

Velázquez Rojas, Manuel. La voz del tiempo. Lima: Perú Joven, 1960.

---. Isla de otoño. Lima: Perú Joven, 1966.

---. Otoño, endechas. Lima: separata de la revista Mercurio Peruano, 1959.

---. Estancias. Lima: La Rama Florida, colección El Timonel, 1960.

---. La gruta de la sirena. Lima: ediciones de La Rama Florida, colección Imago, 1961.

---. Vida continua. Lima: La Rama Florida y Biblioteca Universitaria, 1966. 2a. edición, Instituto Nacional de Cultura, 1971.

---. Recinto. Lima: La Rama Florida, 1968.

---. Surcando el aire oscuro. Lima: Carlos Milla Batres, 1970.

---. Corola parva. México: La Máquina Eléctrica, 1977. 
---. Folios de El Enamorado y la Muerte. Caracas: Monte Avila editores, 1980.

---. Jaikus escritos en un amanecer de otoño. Lima: separata de la revista Lienzo No. 6. Ilustraciones de Takahisa Shirayama, 1986.

---. Retornelo. Lima: ColmilloBlanco. Ilustraciones de Nobuko Tadokoro.

---. Catorce versos dicen... Madrid: Ediciones del Tapir, 1987.

---. Folios de El Enamorado y la Muerte \& El amor y los cuerpos.

Lima: SEGLUSA y Colmillo Blanco, 1988.

---. Poemas 1988. Madrid: Ediciones del Tapir, 1988.

---. Vida continua. Obra poética (1939-1989). Lima: Editorial Colmillo Blanco, Colección de Arena, 1989.

---. Un trino en la ventana vacía. Madrid: Ediciones del Tapir, 1992.

\section{Revistas}

Mar del Sur. No. 10. Lima, marzo-abril 1950.

Literatura. No. 3. Lima, agosto 1959.

Vaca Sagrada. No. 1. Lima 1978.

Hueso Húmero. No. 5-6. Lima, 1980 